\title{
Gabapentin decreases morphine consumption and improves functional recovery following total knee arthroplasty
}

\author{
Hance Clarke MSc MD FRCPC ${ }^{1,2,3}$, Sara Pereira MN-ACNP RN², Deborah Kennedy BSc-PT MSc ${ }^{2}$, \\ lan Gilron MSc MD FRCPC ${ }^{4}$, Joel Katz PhD ${ }^{1,5}$, Jeffrey Gollish MD FRCSC ${ }^{2}$, Joseph Kay MD FRCPC ${ }^{2,3}$
}

H Clarke, S Pereira, D Kennedy, et al. Gabapentin decreases morphine consumption and improves functional recovery following total knee arthroplasty. Pain Res Manage 2009;14(3):217-222.

BACKGROUND: Moderate to severe pain after total knee arthroplasty often interferes with postoperative rehabilitation and delays discharge from hospital. The present study examined the effects of a four-day postoperative gabapentin (GBP) regimen versus placebo on opioid consumption, pain scores and knee flexion, as well as adverse effects, after total knee arthroplasty.

METHODS: After obtaining research ethics board approval and informed consent, 40 patients were enrolled in a randomized, single-blind, placebocontrolled, open-label study. Patients were assigned to one of five groups preoperative placebo/postoperative placebo (G1), preoperative GBP $600 \mathrm{mg} /$ postoperative placebo (G2), preoperative GBP $600 \mathrm{mg} /$ postoperative GBP $100 \mathrm{mg}$ three times per day (G3), preoperative GBP $600 \mathrm{mg} /$ postoperative GBP $200 \mathrm{mg}$ three times per day (G4) and preoperative GBP $600 \mathrm{mg} /$ postoperative GBP $300 \mathrm{mg}$ three times per day (G5). Postoperative GBP or placebo was continued for four days after surgery. Two hours before surgery, all patients received celecoxib $400 \mathrm{mg}$. Based on the above groupings, patients in G1 received placebo medication, whereas patients in G2, G3, G4 and G5 received gabapentin $600 \mathrm{mg} 2 \mathrm{~h}$ preoperatively. All patients received femoral and sciatic nerve blocks, followed by spinal anesthesia. Beginning in the postanesthetic care unit, all patients received a regimen of celecoxib $200 \mathrm{mg}$ every $12 \mathrm{~h}$ for four days and a patient-controlled morphine analgesia pump for $48 \mathrm{~h}$.

RESULTS: Thirty-six patients (G1, n=7; G2, n=7; G3, n=8; G4, n=7; $\mathrm{G} 5, \mathrm{n}=7$ ) completed the study. Data were analyzed by one-way ANOVA followed by a contrast comparing patients who received postoperative GBP (G3, G4 and G5) ( $\mathrm{n}=22)$ with patients who received placebo postoperatively (G1 and G2) ( $n=14)$. Patients who received GBP postoperatively used significantly less patient-controlled morphine analgesia at $24 \mathrm{~h}, 36 \mathrm{~h}$ and $48 \mathrm{~h}(\mathrm{P}<0.05)$. The postoperative GBP patients had significantly better active assisted knee flexion on postoperative days 2 and 3 , with a trend toward better flexion on postoperative day 4. Patients who received GBP postoperatively reported less pruritus than patients who received placebo. There were no differences in pain scores.

CONCLUSIONS: These results support the use of GBP in the acute postoperative period. Further trials are needed to delineate the optimal dose, timing and duration of GBP use following surgery.

Key Words: Functional recovery; Gabapentin; Postsurgical pain; Rehabilitation

$\mathrm{O}$ ver 430,000 total knee arthroplasties (TKAs) are performed in North America each year. In Canada, over 30,000 TKAs are performed annually, with many patients experiencing moderate to severe postoperative pain $(1,2)$. This interferes

\section{La gabapentine réduit la consommation de morphine et améliore le rétablissement fonctionnel après une prothèse totale du genou}

\begin{abstract}
HISTORIQUE : La douleur de modérée à sévère consécutive à une arthroplastie totale du genou, interfère souvent avec la réadaptation postopératoire et retarde le congé hospitalier. La présente étude a mesuré les effets d'un schéma post-opératoire de quatre jours à base de gabapentine (GBP) versus placebo sur la consommation d'opiacés, les indices douloureux et la flexion du genou, de même que sur les effets indésirables après une prothèse totale du genou.
\end{abstract}

MÉTHODE : Après avoir obtenu l'approbation du comité d'éthique de la recherche et les consentements éclairés nécessaires, 40 patients ont été inscrits à une étude randomisée à simple insu, contrôlée par placebo, ouverte. Les patients ont été assignés à l'un de cinq groupes : placebo en préopératoire et post-opératoire (G1), $600 \mathrm{mg}$ de GBP en préopératoire et placebo en post-opératoire (G2), $600 \mathrm{mg}$ de GBP en préopératoire et $100 \mathrm{mg}$ de GBP trois fois par jour en post-opératoire (G3), 600 mg de GBP en préopératoire et $200 \mathrm{mg}$ de GBP trois fois par jour en post-opératoire (G4) et $600 \mathrm{mg}$ de GBP en préopératoire et $300 \mathrm{mg}$ de GBP trois fois par jour en post-opératoire (G5). La GBP ou le placebo en post-opératoire étaient maintenus pendant quatre jours après la chirurgie. Deux heures avant la chirurgie, tous les patients ont reçu $400 \mathrm{mg}$ de célécoxib. Selon les groupes précédents, les patients du G1 ont reçu un placebo, tandis que les patients des G2, G3, G4 et G5 ont reçu de $600 \mathrm{mg}$ gabapentine deux heures avant l'opération. Tous les patients ont reçu des blocs nerveux, fémoraux et sciatiques, suivis d'une anesthésie rachidienne. À leur arrivée à l'unité de soins post-anesthésiques, tous les patients ont reçu $200 \mathrm{mg}$ de célécoxib toutes les 12 heures pendant quatre jours et ils avaient accès à de la morphine administrée par pompe d'auto-analgésie pendant 48 heures. RÉSULTATS : Trente-six patients $(\mathrm{G} 1 \mathrm{n}=7, \mathrm{G} 2 \mathrm{n}=7, \mathrm{G} 3 \mathrm{n}=8, \mathrm{G} 4$ $\mathrm{n}=7, \mathrm{G} 5 \mathrm{n}=7$ ) ont mené l'étude à terme. Les données ont été soumises à une analyse de la variance unilatérale, suivie d'analyse de contraste comparant les patients ayant reçu la GBP en post-opératoire (G3, G4 et G5) $(\mathrm{n}=22)$ aux patients qui avaient reçu un placebo en post-opératoire (G1 et G2) ( $n=14)$. Les patients qui ont reçu de la GBP en post-opératoire utilisaient significativement moins de morphine par autoanalgésie à 24 , 36 et 48 heures $(p<0,05)$. Les patients sous GBP en post-opératoire ont obtenu une flexion active assistée du genou significativement meilleure aux jours 2 et 3 , avec une tendance à une flexion meilleure au $4^{\mathrm{e}}$ jour postopératoire. Les patients ayant reçu la GBP en post-opératoire ont signalé moins de prurit que les patients sous placebo. On n'a noté aucune différence quant aux scores douloureux.

CONCLUSION : Ces résultats appuient l'utilisation de la GBP durant la période post-opératoire immédiate. D’autres études devront être réalisées pour déterminer la dose, le moment et la durée optimaux du traitement par GBP après la chirurgie.

with postoperative rehabilitation and subsequent discharge from hospital, and leads to the development of chronic pain in $30 \%$ of patients (3). Standard perioperative pain management often relies on opioids as the primary pain medication, but they

${ }^{1}$ Department of Anesthesia and Pain Management, Toronto General Hospital; ${ }^{2}$ Holland Orthopedic and Arthritic Centre, Sunnybrook Health Sciences Centre; ${ }^{3}$ Department of Anesthesia, University of Toronto, Toronto; ${ }^{4}$ Departments of Anesthesiology and Pharmacology $\mathbb{E}$ Toxicology, Queen's University, Kingston; ${ }^{5}$ Department of Psychology and School of Kinesiology and Health Science, York University, Toronto, Ontario

Correspondence: Dr Hance Clarke, Department of Anesthesia and Pain Management, Toronto General Hospital, Acute Pain Research Unit, 200 Elizabeth Street, Eaton North 3 EB 317, Toronto, Ontario M5G 2C4. Telephone 416-340-4800 ext 6649, fax 416-340-3698,

e-mail hance.clarke@utoronto.ca 
are relatively ineffective for severe movement-associated pain, and are associated with significant side effects such as nausea, vomiting, sedation, pruritus, constipation, urinary retention and respiratory depression (4). The preoperative use of gabapentin (GBP), a nonopioid medication, has been shown to be effective in reducing opioid use and accelerating functional recovery for $48 \mathrm{~h}$ after anterior cruciate ligament repair (5).

GBP, a structural analogue of gamma-amino butyric acid, has been used as an anticonvulsant and antinociceptive drug. Its main binding site is the alpha-2-delta subunit of voltagedependent calcium channels (6). GBP is effective for neuropathic pain, diabetic neuropathy, postherpetic neuralgia and reflex sympathetic dystrophy (7). GBP has antihyperalgesic actions that selectively affect central sensitization (8). Over the past eight years, many trials have examined the efficacy of GBP for the treatment of early postsurgical pain. The surgical populations studied include abdominal or pelvic surgery (9-16), musculoskeletal surgery $(5,17-23)$, head and neck surgery (24-26), breast surgery (27-30), varicocele surgery (31) and thoracic surgery (32). Of these randomized controlled trials, most consisted of a single dose of GBP given before surgery. Only four of the above trials failed to demonstrate a decrease in pain scores or an opioidsparing effect in the early postsurgical period $(10,17,18,21)$.

The optimal preoperative dose of GBP has been evaluated in a dose-response study by Pandey et al (19), who randomly assigned patients undergoing lumbar discectomy to receive a one-time dose of placebo, or GBP $300 \mathrm{mg}, 600 \mathrm{mg}, 900 \mathrm{mg}$ or $1200 \mathrm{mg}$ preoperatively. The optimal dose was $600 \mathrm{mg}$; at higher doses (900 and $1200 \mathrm{mg}$ ), an analgesic ceiling effect was observed, in which patients exhibited more side effects with no additional reduction in pain.

Much more work needs to be done with regard to the optimal dosing of GBP in various surgical populations and this medication's efficacy at treating postoperative pain beyond the immediate $24 \mathrm{~h}$ or $48 \mathrm{~h}$. Because many of the GBP trials published to this point have demonstrated a significant reduction in movementevoked pain $(5,11,14,16,24,27,29)$, we hypothesized that continuing GBP into the rehabilitation period would lead to decreased pain during rehabilitation treatments and improved functional recovery (ie, a greater range of motion).

There are several novel aspects to the present study. To begin, the present trial is the first to examine the effect of GBP in patients undergoing TKA. Second, this is the first trial to use neuraxial regional anesthesia as the primary anesthetic modality. Until the recent study by Turan et al (33) demonstrating that premedication with oral GBP (1.2 g) decreased tourniquetrelated pain and improved the quality of anesthesia during hand surgery under intravenous regional anesthesia, all other studies used general anesthesia with volatile agents as the main anesthetic technique. Furthermore, in the present study, GBP was administered for four days after surgery to determine whether this medication helps to improve functional outcomes in the acute hospital rehabilitation period. Menigaux et al (5) found that a single dose of GBP $1200 \mathrm{mg}$ preoperatively improved first and maximal passive and active knee flexions at $24 \mathrm{~h}$ and $48 \mathrm{~h}$ after surgery in the GBP group compared with the control group.

The concept of multimodal analgesia involves the use of different classes of analgesic agents with different routes of administration to provide superior pain relief at rest and after movement, and to reduce opioid consumption and analgesic-related adverse effects $(34,35)$. Although many clinical trials demonstrate the effectiveness of multimodal analgesia, positive results may not translate into clinical practice $(36,37)$. One reason may be that comparing a treatment to a placebo lacks clinical applicability. To adequately treat pain in the perioperative period, multimodal treatments targeting the multiple cellular mechanisms that trigger the pain response must be compared with a clinically relevant control condition. The present study was designed to evaluate the efficacy of GBP in the context of a clinically relevant, multimodal regimen, including preoperative spinal anesthesia (bupivacaine), nonsteroidal anti-inflammatory drugs (celecoxib), and peripheral femoral and sciatic nerve blocks (with ropivacaine).

\section{METHODS}

The present study was approved by the Sunnybrook Health Sciences Centre Research Ethics Board, and all patients gave informed, written consent to participate. Patients between 18 and 75 years of age with an American Society of Anesthesiologists physical status score of I or II undergoing TKA were eligible for this study. Patients were not eligible if they had a known allergy to any of the medications being used; a history of drug or alcohol abuse; a history of taking chronic pain medications (ie, slow-release preparations of opioids, which would compromise the study results, given that morphine consumption was the primary outcome); a history of taking GBP or pregabalin; rheumatoid arthritis; a psychiatric disorder; a history of diabetes with impaired renal function; or a body mass index of greater than $40 \mathrm{~kg} / \mathrm{m}^{2}$; or if they were unable or unwilling to use patient-controlled analgesia (PCA).

Patients were recruited at their preoperative assessment visit approximately one to two weeks in advance of their surgery. All subjects were screened, after which the study protocol, as well as the use of the PCA pump and a $10 \mathrm{~cm}$ visual analogue scale (VAS) for pain measurement (with end points of 'no pain' and 'worst pain possible'), were explained. A computer-generated randomization schedule was used to assign patients in blocks of five to one of the treatment groups. The schedule was created by the hospital investigational pharmacy, which was otherwise not involved in the clinical care of the patients or in the conduct of the trial. On the day of surgery, patients were randomly assigned to one of five treatment arms: preoperative placebo/postoperative placebo (G1), preoperative GBP $600 \mathrm{mg} /$ postoperative placebo (G2), preoperative GBP $600 \mathrm{mg} /$ postoperative GBP $100 \mathrm{mg}$ three times per day (G3), preoperative GBP $600 \mathrm{mg} /$ postoperative GBP 200 mg three times per day (G4) and preoperative GBP $600 \mathrm{mg} /$ postoperative GBP $300 \mathrm{mg}$ three times per day (G5). Two hours before surgery, all patients received celecoxib $400 \mathrm{mg}$. Based on the above groupings, patients in G1 received placebo medication, whereas patients in G2, G3, G4 and G5 received GBP $600 \mathrm{mg} 2 \mathrm{~h}$ preoperatively. Postoperative GBP or placebo was continued for four days after surgery beginning $8 \mathrm{~h}$ after the preoperative dose.

All patients were prepared for surgery in a specialized block area. An intravenous infusion of lactated Ringer's solution was started after insertion of an $18 \mathrm{~g}$ intravenous cannula. Blood pressure, electrocardiography and oximetry monitors were applied. Intravenous midazolam $1 \mathrm{mg}$ to $3 \mathrm{mg}$ was administered to achieve anxiolysis. Femoral and sciatic nerve blocks were performed using a nerve stimulator and ultrasound technique to localize the nerves at less than $0.5 \mathrm{~mA}$. Ropivacaine $0.5 \%$ 
TABLE 1

Demographic characteristics and duration of surgery

\begin{tabular}{lccccc}
\hline Variable & $\mathbf{G 1}(\mathbf{n}=7)$ & $\mathbf{G 2}(\mathbf{n}=7)$ & $\mathbf{G 3}(\mathbf{n}=8)$ & $\mathbf{G 4}(\mathbf{n}=7)$ & $\mathbf{G 5}(\mathbf{n}=7)$ \\
\hline Age, years & $60.7 \pm 6.6$ & $63.9 \pm 5.6$ & $57.3 \pm 7.4$ & $65.8 \pm 6.5$ & $62.33 \pm 6.6$ \\
$\begin{array}{c}\text { Sex, male/ } \\
\text { female, } \mathrm{n}\end{array}$ & $3 / 4$ & $2 / 5$ & $4 / 4$ & $3 / 4$ & $2 / 5$ \\
$\begin{array}{c}\text { Body mass } \\
\text { index, } \mathrm{kg} / \mathrm{m}^{2}\end{array}$ & $31.0 \pm 8.5$ & $34.2 \pm 6.1$ & $28.1 \pm 4.1$ & $29.5 \pm 3.6$ & $28.0 \pm 2.2$ \\
$\begin{array}{c}\text { Duration of } \\
\text { surgery, min }\end{array}$ & $77.0 \pm 20.3$ & $58.2 \pm 17.2$ & $63.3 \pm 25.7$ & $68.2 \pm 27.0$ & $65.8 \pm 27.0$ \\
\hline
\end{tabular}

Data are presented as mean $\pm S D$ unless otherwise specified. No significant differences were observed among groups. Preoperative dose/postoperative regimen: G1 Placebo/placebo three times per day (TID); G2 Gabapentin (GBP) 600 mg/placebo TID; G3 GBP 600 mg/GBP 100 mg TID; G4 GBP 600 mg/GBP $200 \mathrm{mg}$ TID; G5 GBP 600 mg/GBP 300 mg TID

(20 L), with an approximate mean duration of action of $15 \mathrm{~h}$, was deposited adjacent to each nerve (38). Spinal anesthesia was performed in the lateral decubitus or sitting position. After subcutaneous infiltration with lidocaine $1 \%$, and using a midline approach, a 25 gauge Whitacre needle was inserted at the L3 to L4, L4 to L5 or L5 to S1 interspace, with the aperture directed to the side of surgery. When free flow of cerebrospinal fluid was obtained, $10 \mathrm{mg}$ of $0.5 \%$ hypobaric bupivacaine with $10 \mu \mathrm{g}$ of fentanyl was injected. In all groups, the total volume injected to the subarachnoid space was $2.2 \mathrm{~mL}$, with aspiration at the end of injection to ensure that all the drug was injected intrathecally. The patient was then placed in the lateral decubitus position with the side of surgery uppermost. Patients were then transferred to the operating room, where monitors were reapplied, supplemental oxygen was provided and sedation was provided by an intravenous propofol infusion $(25 \mu \mathrm{g} / \mathrm{kg} / \mathrm{min}$ to $100 \mu \mathrm{g} / \mathrm{kg} \mathrm{min})$ until the end of surgery. The attending anesthesiologist was not involved in the patients' evaluation postoperatively.

Beginning postoperatively in the postanesthesia care unit, all patients, regardless of treatment group, received a standard postoperative regimen of celecoxib $200 \mathrm{mg}$ every $12 \mathrm{~h}$ for four days as well as an intravenous PCA morphine pump.

VAS pain scores at rest were obtained at the time of PCA hookup in the postanesthesia care unit $(0 \mathrm{~h})$ and every $4 \mathrm{~h}$; scores were collected by the Holland Orthopedic and Arthritic Centre (Toronto, Ontario) nursing staff (who had no investment in the study) for the following $48 \mathrm{~h}$. All pain scores in the present study were measured with patients in a resting position. The PCA pump was set to deliver a $1 \mathrm{mg}$ bolus of morphine per demand with a 5 min lockout and no background infusion. All patients were instructed to maintain their VAS pain score at less than 4 out of 10 . If the VAS pain score was 5 or greater at rest on two consecutive pain assessments, the dose of intravenous PCA morphine was increased to $1.5 \mathrm{mg}$ per demand. In addition, at each $4 \mathrm{~h}$ time point, the incidence and severity of sedation, nausea, vomiting and pruritus were assessed.

Postoperatively, all patients followed a primary knee replacement care pathway, accompanied by a standardized rehabilitation treatment protocol. All patients began a full weight-bearing regimen, and participated in a progressive rehabilitation program for range of motion, strengthening, balance and ambulation beginning the first day after surgery. On postoperative days (PODs) 2 , 3 and 4, active assisted knee flexion range of motion was assessed for all patients by a qualified physiotherapist. Degrees of motion were recorded using a standard long-arm goniometer. The
TABLE 2

Cumulative morphine consumption ( $\mathrm{mg}$ ) after surgery

\begin{tabular}{lrllll}
\hline $\begin{array}{l}\text { Time after } \\
\text { surgery, } \mathbf{h}\end{array}$ & $\mathbf{G 1}(\mathbf{n}=\mathbf{7})$ & $\mathbf{G} \mathbf{2}(\mathbf{n}=\mathbf{7})$ & $\mathbf{G 3}(\mathbf{n}=\mathbf{8})$ & $\mathbf{G} 4(\mathbf{n}=\mathbf{7})$ & $\mathbf{G 5}(\mathbf{n}=\mathbf{7})$ \\
\hline 12 & $19.71 \pm 14.6$ & $15.6 \pm 8.4$ & $18.5 \pm 8.4$ & $10.3 \pm 6.5$ & $11.1 \pm 9.4$ \\
24 & $63.8 \pm 36.5$ & $38.4 \pm 23.8$ & $38.2 \pm 21.0$ & $29.7 \pm 20.9$ & $25.8 \pm 18.6$ \\
36 & $91.2 \pm 59.9$ & $61.7 \pm 41.0$ & $60.2 \pm 19.1$ & $44.5 \pm 24.6$ & $42.2 \pm 21.3$ \\
48 & $95.2 \pm 59.7$ & $104.4 \pm 17.2$ & $73.4 \pm 28.8$ & $54.0 \pm 35.7$ & $44.0 \pm 20.2$ \\
\hline
\end{tabular}

Data are presented as mean $\pm S D$. No significant differences were observed among groups. Preoperative dose/postoperative regimen: G1 Placebo/placebo three times per day (TID); G2 Gabapentin (GBP) $600 \mathrm{mg} / \mathrm{placebo}$ TID; G3 GBP 600 mg/GBP 100 mg TID; G4 GBP 600 mg/GBP 200 mg TID; G5 GBP $600 \mathrm{mg} / \mathrm{GBP} 300 \mathrm{mg}$ TID

goniometer was centred on the axis point of the knee with the greater trochanter at the hip as the proximal reference point and the lateral malleolus at the ankle as the distal reference point. Active assisted knee flexion was measured with the patient in a sitting position and a towel placed under the proximal thigh. Following standard treatment, patients were asked to bend their knee as far as possible, at which point the therapist applied overpressure and recorded the measurement in degrees. The assessment of the range of knee motion in patients with knee osteoarthritis has been shown to have good reliability (39).

On completion of the present study, the data were entered into the statistical software package SPSS 15.0 (SPSS Inc, USA). An a priori sample size calculation is lacking for the present study because the aim was to generate data for a larger study. Demographic and clinical variables were compared among the groups using one-way ANOVA or a $\chi^{2}$ test as appropriate. Pain scores and morphine consumption were analyzed by ANOVA for repeated measures. Due to the small numbers of patients recruited in each group, a contrast comparing patients who received postoperative GBP (G3, G4 and G5) with patients who received postoperative placebo (G1 and G2) was calculated. This was also performed using an ANOVA for repeated measures. The degrees of active assisted knee flexion were compared using unpaired $t$ tests. Finally, Mann-Whitney U nonparametric tests were performed to determine whether there was an association between adverse effects and study group assignment. A value of $\mathrm{P}<0.05$ was considered to be statistically significant.

\section{RESULTS}

A total of 64 patients were approached and screened for interest in participating in the present study. Twenty-four patients declined to participate in the study, while the other 40 patients were successfully recruited. Four patients refused to complete the medication regimen and requested to be withdrawn from the study. Thus, 36 patients completed the study - seven patients in G1, seven in G2, eight in G3, seven in G4 and seven in G5. A protocol-compliant approach to data analysis was used.

The groups were comparable with respect to age, body mass index, sex and duration of surgery (Table 1). Overall, significant differences among groups (G1 to G5) were not found in mean morphine consumption or pain scores (Tables 2 and 3 ). However, a planned comparison of patients who received postoperative GBP (G3, G4 and G5) ( $\mathrm{n}=22$ ) with patients who received placebo medications postoperatively (G1 and G2) $(n=14)$ found significant differences. Demographic data were similar between the two contrasted groups (Table 4). Patients who received 
TABLE 3

Mean visual analogue scale rest pain scores after surgery

\begin{tabular}{lclccc}
\hline $\begin{array}{l}\text { Time after } \\
\text { surgery, } \mathbf{h}\end{array}$ & $\mathbf{G} \mathbf{1}(\mathbf{n}=\mathbf{7})$ & $\mathbf{G} \mathbf{2}(\mathbf{n}=\mathbf{7})$ & $\mathbf{G} \mathbf{3}(\mathbf{n}=\mathbf{8})$ & $\mathbf{G} \mathbf{4}(\mathbf{n}=\mathbf{7})$ & $\mathbf{G 5}(\mathbf{n}=\mathbf{7})$ \\
\hline In PACU & $13.85 \pm 26.7$ & $0.28 \pm 0.7$ & $0.0 \pm 0.0$ & $11.0 \pm 20.0$ & $0.1 \pm 0.4$ \\
12 & $38.7 \pm 28.5$ & $33.1 \pm 27.5$ & $24.5 \pm 38.2$ & $17.7 \pm 22.0$ & $11.3 \pm 5.8$ \\
24 & $51.0 \pm 21.8$ & $41.7 \pm 24.8$ & $29.8 \pm 20.4$ & $29.5 \pm 30.1$ & $45.6 \pm 29.2$ \\
36 & $36.4 \pm 19.5$ & $45.0 \pm 21.3$ & $36.4 \pm 26.4$ & $29.3 \pm 29.6$ & $34.5 \pm 22.8$ \\
48 & $18.7 \pm 22.8$ & $17.8 \pm 18.2$ & $17.0 \pm 18.2$ & $10.0 \pm 9.7$ & $9.0 \pm 7.3$ \\
\hline
\end{tabular}

Data are presented as mean $\pm S D$. No significant differences were observed among groups. Preoperative dose/postoperative regimen: G1 Placebo/placebo three times per day (TID); G2 Gabapentin (GBP) 600 mg/placebo TID; G3 GBP 600 mg/GBP $100 \mathrm{mg}$ TID; G4 GBP 600 mg/GBP $200 \mathrm{mg}$ TID; G5 GBP $600 \mathrm{mg} / \mathrm{GBP} 300 \mathrm{mg}$ TID. PACU Postanesthetic care unit

\section{TABLE 4}

Demographic characteristics for postoperative gabapentin versus placebo-treated patients

\begin{tabular}{lcc}
\hline Variable & $\begin{array}{c}\text { Postoperative } \\
\text { placebo }(\mathbf{n = 1 4})\end{array}$ & $\begin{array}{c}\text { Postoperative } \\
\text { gabapentin }(\mathbf{n = 2 2})\end{array}$ \\
\hline Age, years & $62.3 \pm 6.1$ & $62.4 \pm 7.2$ \\
Sex, male/female, $\mathrm{n}$ & $5 / 9$ & $9 / 13$ \\
Body mass index, $\mathrm{kg} / \mathrm{m}^{2}$ & $32.0 \pm 7.2$ & $28.9 \pm 3.7$ \\
Duration of surgery, $\mathrm{min}$ & $68.7 \pm 16.8$ & $67.0 \pm 17.3$
\end{tabular}

Data are presented as mean $\pm S D$ unless otherwise specified. No significant differences were observed between patients who received postoperative placebo versus postoperative gabapentin. Consistent with data shown in Table 3, mean postoperative pain scores were not different between these two groups

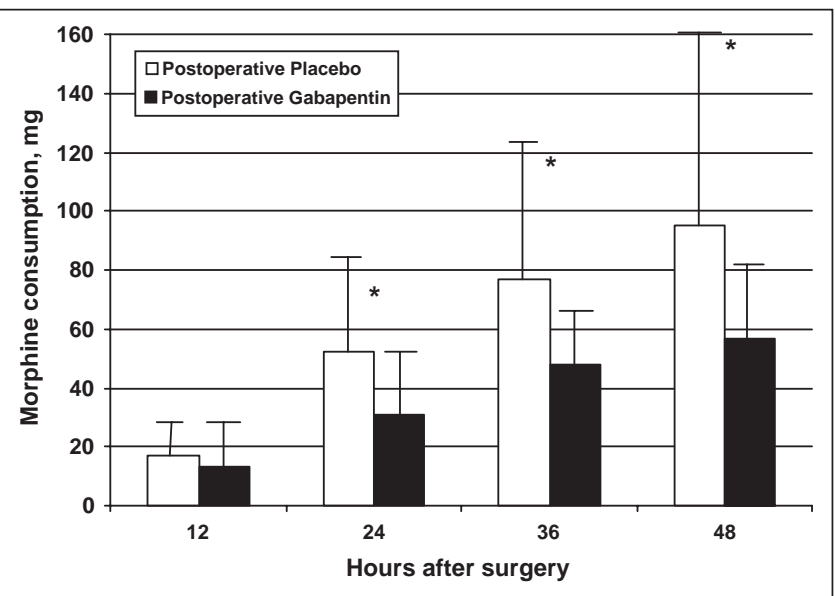

Figure 1) Cumulative morphine consumption after total knee arthroplasty showing a comparison of patients who received gabapentin postoperatively versus placebo postoperatively. Patients who received gabapentin postoperatively used significantly less patient-controlled morphine analgesia (mean $\pm \mathrm{SD})$ at $24 \mathrm{~h}(31 \pm 20 \mathrm{mg}$ versus $52 \pm 32 \mathrm{mg}), 36 \mathrm{~h}(48 \pm 22 \mathrm{mg}$ versus $77 \pm 48 \mathrm{mg})$ and $48 \mathrm{~h}$ (57 $\pm 30 \mathrm{mg}$ versus $95 \pm 57 \mathrm{mg}$ ) postsurgery. The absence of a difference at $12 \mathrm{~h}$ reflects the ongoing analgesic effect of the peripheral nerve blocks. All patients received femoral and sciatic nerve blocks with ropivacaine $0.5 \%$ (20 $\mathrm{mL}$ adjacent to each nerve) for postoperative pain (half-life $14 \pm 3 \mathrm{~h}$ ). $* \mathrm{P}<0.05$

postoperative GBP versus placebo used significantly less PCA morphine (mean $\pm \mathrm{SD})$ at $24 \mathrm{~h}(31 \pm 20 \mathrm{mg}$ versus $52 \pm 32 \mathrm{mg})$, $36 \mathrm{~h}(48 \pm 22 \mathrm{mg}$ versus $77 \pm 48 \mathrm{mg})$ and $48 \mathrm{~h}(57 \pm 30 \mathrm{mg}$ versus $95 \pm 57 \mathrm{mg}$, all $\mathrm{P}<0.05)$ postsurgery (Figure 1 ). Patients who

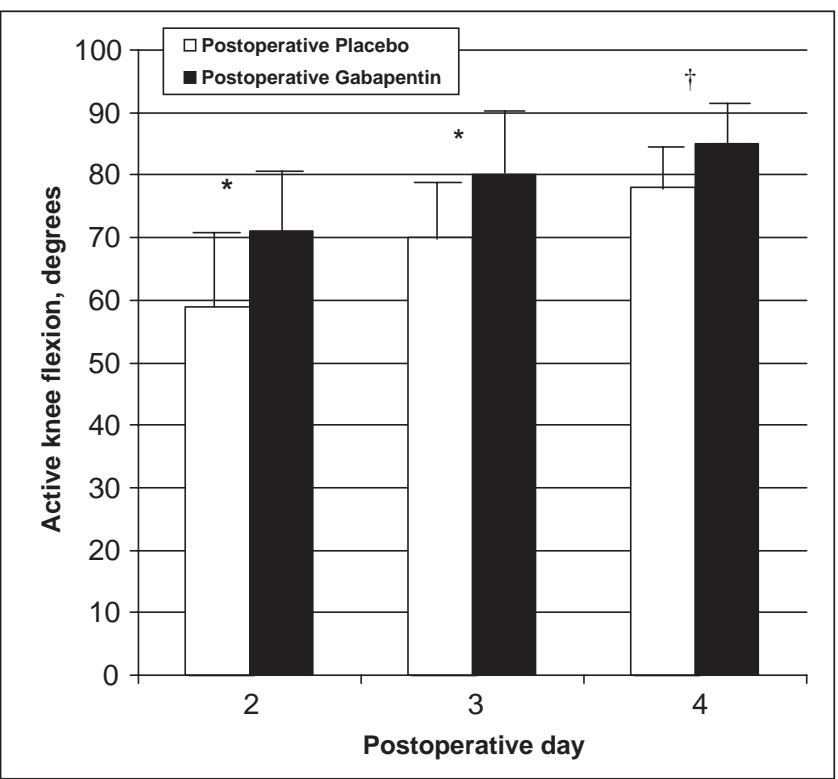

Figure 2) Active knee flexion post-total knee arthroplasty shown for patients who received postoperative gabapentin versus placebo. Patients who received postoperative gabapentin versus placebo had significantly better active knee flexion on postoperative day (POD) 2 $\left(71^{\circ} \pm 12^{\circ}\right.$ versus $\left.59^{\circ} \pm 12^{\circ}\right)$ and POD $3\left(80^{\circ} \pm 9^{\circ}\right.$ versus $\left.70^{\circ} \pm 9^{\circ}\right)$, with a trend toward better flexion on POD $4\left(85^{\circ} \pm 9^{\circ}\right.$ versus $\left.78^{\circ} \pm 9^{\circ}\right) . * P<0.05 ; \dagger P=0.08$

\section{TABLE 5}

Frequency of adverse effects over $48 \mathrm{~h}$

\begin{tabular}{lcc}
\hline Adverse effect & $\begin{array}{c}\text { Postoperative } \\
\text { placebo, } \mathbf{n}\end{array}$ & $\begin{array}{c}\text { Postoperative } \\
\text { gabapentin, } \mathbf{n}\end{array}$ \\
\hline Sedation & 9 & 14 \\
Nausea & 9 & 11 \\
Vomiting & 5 & 4 \\
Pruritus* & 11 & 5 \\
Dizziness & 6 & 3 \\
\hline *Indicates significant difference, $P<0.05$ &
\end{tabular}

received postoperative GBP versus placebo had significantly better active knee flexion on $\mathrm{POD} 2\left(71^{\circ} \pm 12^{\circ}\right.$ versus $59^{\circ} \pm 12^{\circ}$, $\mathrm{P}<0.05)$, POD $3\left(80^{\circ} \pm 9^{\circ}\right.$ versus $\left.70^{\circ} \pm 9^{\circ}, \mathrm{P}<0.05\right)$, with a trend toward better flexion on $\mathrm{POD} 4\left(85^{\circ} \pm 9^{\circ}\right.$ versus $\left.78^{\circ} \pm 9^{\circ}, \mathrm{P}=0.08\right)$ (Figure 2 ). Patients who received GBP postoperatively reported significantly less pruritus than patients who received placebo $(\mathrm{P}<0.05)$. The two groups did not differ significantly in terms of sedation, nausea, vomiting or dizziness scores (Table 5). There were no reports of postdural puncture headache, and all patients had successful spinal anesthesia.

\section{DISCUSSION}

The efficacy of GBP in reducing opioid consumption has been well documented $(5,9,11,14-16,19,33)$. Several meta-analyses have convincingly demonstrated that preoperative GBP leads to a reduction in postoperative opioid use and a reduction in postoperative pain scores (40-42). Furthermore, GBP has demonstrated the ability to improve functional recovery after total abdominal hysterectomy (11) and anterior cruciate ligament repair (5). The results of the present study suggest that perioperative GBP, when continued for four days postoperatively, not only reduces opioid consumption but also leads to an 
improvement in active assisted knee flexion. There were no differences in pain scores during this trial. A significant increase in the incidence of pruritus was found in the patients who received postoperative placebo, which we attribute to the increased morphine use by these patients. This interpretation is consistent with the results of a recent study by Sheen et al (43) showing that patients who received preoperative GBP demonstrated less pruritus following intrathecal morphine injection than patients receiving placebo medications.

GBP has been studied extensively in surgical populations that were given general anesthesia as the primary anesthetic modality. One of the major concerns for health care providers is the incidence of sedation that has been reported in several studies $(11,12,19,25)$. The postulated main binding site of GBP is the alpha-2-delta subunit of voltage-dependent calcium channels (6). Recent studies also demonstrate a link to central inhibitory gabaergic pathways in the central nervous system $(44,45)$, and research continues in an effort to elucidate the cellular mechanisms mediating the actions of the gabapentinoids. Given the likelihood of a central depressant mechanism of GBP, the interaction of GBP and central inhibitory anesthetic agents may be cumulative in the immediate postoperative period; thus, health care providers often must adjust the dose of intraoperative opioids to avoid excessive sedation when using GBP perioperatively. The use of GBP with regional anesthesia (spinal or epidural analgesia, and peripheral nerve blocks) as the primary surgical modality, provides a robust neuronal blockade for hours after surgery. Spinal anesthesia was chosen as the primary anesthetic modality and the peripheral (ie, femoral and sciatic) nerve blocks were adjuncts for postoperative pain (12 \pm 3 h) (38). Table 2 and Figure 1 demonstrate the effectiveness of our spinal and peripheral nerve blockade regimen. All patients used very little morphine within the first $12 \mathrm{~h}$ of surgery. Once the peripheral nerve blocks wore off, the opioid-sparing effect of GBP became evident. Turan et al (23) found that GBP (1200 mg/day) as an adjunct to epidural analgesia decreased pain and analgesic consumption in patients who had undergone lower extremity surgical procedures. In contrast, Adam et al (17) found that a single preoperative dose of $800 \mathrm{mg}$ of GBP did not augment postoperative analgesia in patients given interscalene brachial plexus blocks for arthroscopic shoulder surgery. It is clear that administration of GBP in conjunction with regional anesthesia needs further investigation with respect to the timing and length of postoperative administration.

Osteoarthritis, the most common reason for TKA, accounts for more difficulty with climbing stairs and walking than any

\section{REFERENCES}

1. Cremeans-Smith JK, Boarts JM, Greene K, Delahanty DL. Patients' reasons for electing to undergo total knee arthroplasty impact postoperative pain severity and range of motion. J Behav Med 2009;32:223-33.

2. Fischer HB, Simanski CJ, Sharp C, et al. A procedure-specific systematic review and consensus recommendations for postoperative analgesia following total knee arthroplasty. Anaesthesia 2008;63:1105-23.

3. Goldstein DH, Ellis J, Brown R, et al. Recommendations for improved acute pain services: Canadian collaborative acute pain initiative. Pain Res Manage 2004;9:123-30.

4. Strassels SA, McNicol E, Suleman R. Postoperative pain management: A practical review, part 2. Am J Health Syst Pharm 2005;62:2019-25.

5. Menigaux C, Adam F, Guignard B, Sessler DI, Chauvin M. Preoperative gabapentin decreases anxiety and improves early other disease $(46,47)$. Because one of the primary goals of TKA is to improve physical function, this is an excellent population in which to study the effects of GBP on functional outcomes. As stated earlier, many trials have demonstrated an improvement in movement-evoked postsurgical pain $(5,11,14,16,24,27,29)$. By including a physical measure (active and passive knee flexion), Menigaux et al (5) demonstrated that GBP enhanced mobilization of the knee joint after anterior cruciate ligament repair, thus potentially improving functional recovery. The results of the present study also show improved physical function in patients who received GBP for four days after surgery (Figure 2) and suggest that further research is needed to evaluate the long-term functional outcomes associated with perioperative GBP administration.

There are several limitations of the current study. First, the study was significantly underpowered to determine a doseresponse effect of GBP. Several hundred patients would be needed to conduct such a trial. Second, this trial was not double blinded. However, neither the patients nor the physiotherapists involved in the assessment of functional outcomes were aware of the medication or doses received. Finally, there is much debate in the arthroplasty literature as to the value of an isolated physiotherapy measure of function to comprehensively measure outcome $(48,49)$. Therefore, future research should incorporate a number of functional outcome measures, both self-report- and rehabilitation-based, to monitor recovery following TKA. Measures such as the 6 min walk test $(50,51)$, the timed up and go test $(52,53)$ and a timed stair test $(54-56)$ have all demonstrated reliability and sensitivity to change within the knee arthroplasty population (39).

ACKNOWLEDGEMENTS: The authors thank the study coordinator, Beth Goudie RN, as well as the Holland Orthopedic and Arthritic Centre's nursing staff and the pharmacy and physiotherapy departments for all their hard work and support. They also thank Eileen Halket RN and the Acute Pain Research team at the Toronto General Hospital for their many hours of hard work.

FUNDING: Joel Katz is supported by a Canada Research Chair in Health Psychology at York University. This work was performed in partial fulfillment of Hance Clarke's doctoral dissertation. Ian Gilron has received funding in the form of research support and/or consulting fees from Pfizer Inc, Novopharm and Pharmascience, all of whom manufacture GBP.

functional recovery from knee surgery. Anesth Analg 2005;100:1394-9.

6. Cheng JK, Chiou LC. Mechanisms of the antinociceptive action of gabapentin. J Pharmacol Sci 2006;100:471-86.

7. Hahn K, Arendt G, Braun JS, et al. A placebo-controlled trial of gabapentin for painful HIV-associated sensory neuropathies. J Neurol 2004;251:1260-6.

8. Rose MA, Kam PC. Gabapentin: Pharmacology and its use in pain management. Anaesthesia 2002;57:451-62.

9. Dierking G, Duedahl TH, Rasmussen ML, et al. Effects of gabapentin on postoperative morphine consumption and pain after abdominal hysterectomy: A randomized, double-blind trial. Acta Anaesthesiol Scand 2004;48:322-7.

10. Fassoulaki A, Stamatakis E, Petropoulos G, Siafaka I, Hassiakos D, Sarantopoulos C. Gabapentin attenuates late but not acute pain after abdominal hysterectomy. Eur J Anaesthesiol 2006;23:136-41. 
11. Gilron I, Orr E, Tu D, O’Neill JP, Zamora JE, Bell AC. A placebocontrolled randomized clinical trial of perioperative administration of gabapentin, rofecoxib and their combination for spontaneous and movement-evoked pain after abdominal hysterectomy. Pain 2005;113:191-200.

12. Pandey CK, Priye S, Singh S, Singh U, Singh RB, Singh PK. Preemptive use of gabapentin significantly decreases postoperative pain and rescue analgesic requirements in laparoscopic cholecystectomy. Can J Anaesth 2004;51:358-63.

13. Pandey CK, Singhal V, Kumar M, et al. Gabapentin provides effective postoperative analgesia whether administered preemptively or post-incision. Can J Anaesth 2005;52:827-31.

14. Rorarius MG, Mennander S, Suominen P, et al. Gabapentin for the prevention of postoperative pain after vaginal hysterectomy. Pain 2004;110:175-81.

15. Turan A, Karamanlioglu B, Memis D, Usar P, Pamukcu Z, Ture $\mathrm{M}$. The analgesic effects of gabapentin after total abdominal hysterectomy. Anesth Analg 2004;98:1370-3.

16. Turan A, White PF, Karamanlioglu B, et al. Gabapentin: An alternative to the cyclooxygenase- 2 inhibitors for perioperative pain management. Anesth Analg 2006;102:175-81.

17. Adam F, Menigaux C, Sessler DI, Chauvin M. A single preoperative dose of gabapentin ( 800 milligrams) does not augment postoperative analgesia in patients given interscalene brachial plexus blocks for arthroscopic shoulder surgery. Anesth Analg 2006;103:1278-82.

18. Leung JM, Sands LP, Rico M, et al. Pilot clinical trial of gabapentin to decrease postoperative delirium in older patients. Neurology 2006;67:1251-3.

19. Pandey CK, Navkar DV, Giri PJ, et al. Evaluation of the optimal preemptive dose of gabapentin for postoperative pain relief after lumbar diskectomy: A randomized, double-blind, placebocontrolled study. J Neurosurg Anesthesiol 2005;17:65-8.

20. Pandey CK, Sahay S, Gupta D, et al. Preemptive gabapentin decreases postoperative pain after lumbar discoidectomy. Can J Anaesth 2004;51:986-9.

21. Radhakrishnan M, Bithal PK, Chaturvedi A. Effect of preemptive gabapentin on postoperative pain relief and morphine consumption following lumbar laminectomy and discectomy: A randomized, double-blinded, placebo-controlled study. J Neurosurg Anesthesiol 2005;17:125-8.

22. Turan A, Karamanlioglu B, Memis D, et al. Analgesic effects of gabapentin after spinal surgery. Anesthesiology 2004;100:935-8.

23. Turan A, Kaya G, Karamanlioglu B, Pamukcu Z, Apfel CC. Effect of oral gabapentin on postoperative epidural analgesia. Br J Anaesth 2006;96:242-6.

24. Al-Mujadi H, A-Refai AR, Katzarov MG, Dehrab NA, Batra YK, Al-Qattan AR. Preemptive gabapentin reduces postoperative pain and opioid demand following thyroid surgery. Can J Anaesth 2006;53:268-73.

25. Mikkelsen S, Hilsted KL, Andersen PJ, et al. The effect of gabapentin on post-operative pain following tonsillectomy in adults. Acta Anaesthesiol Scand 2006;50:809-15.

26. Turan A, Memis D, Karamanlioglu B, Yagiz R, Pamukcu Z, Yavuz E. The analgesic effects of gabapentin in monitored anesthesia care for ear-nose-throat surgery. Anesth Analg 2004;99:375-8.

27. Dirks J, Fredensborg BB, Christensen D, Fomsgaard JS, Flyger H, Dahl JB. A randomized study of the effects of single-dose gabapentin versus placebo on postoperative pain and morphine consumption after mastectomy. Anesthesiology 2002;97:560-4.

28. Fassoulaki A, Patris K, Sarantopoulos C, Hogan Q. The analgesic effect of gabapentin and mexiletine after breast surgery for cancer. Anesth Analg 2002;95:985-91.

29. Fassoulaki A, Triga A, Melemeni A, Sarantopoulos C. Multimodal analgesia with gabapentin and local anesthetics prevents acute and chronic pain after breast surgery for cancer. Anesth Analg 2005;101:1427-32.

30. Parsa AA, Sprouse-Blum AS, Jackowe DJ, Lee M, Oyama J, Parsa FD. Combined preoperative use of celecoxib and gabapentin in the management of postoperative pain. Aesthetic Plast Surg 2009;33:98-103.

31. Koc S, Memis D, Sut N. The preoperative use of gabapentin, dexamethasone, and their combination in varicocele surgery: A randomized controlled trial. Anesth Analg 2007;105:1137-42.

32. Huot MP, Chouinard P, Girard F, Ruel M, Lafontaine ER, Ferraro P. Gabapentin does not reduce post-thoracotomy shoulder pain: A randomized, double-blind placebo-controlled study. Can J Anaesth 2008;55:337-43.

33. Turan A, White PF, Karamanlioglu B, Pamukcu Z. Premedication with gabapentin: The effect on tourniquet pain and quality of intravenous regional anesthesia. Anesth Analg 2007;104:97-101.

34. Brown AK, Christo PJ, Wu CL. Strategies for postoperative pain management. Best Pract Res Clin Anaesthesiol 2004;18:703-17.

35. Joshi GP. Multimodal analgesia techniques and postoperative rehabilitation. Anesthesiol Clin North Am 2005;23:185-202.

36. Hsieh M, Yealy DM. Are we ignoring the evidence? Acad Emerg Med 2005;12:461-2.

37. Marshall ML. Strategies for success: Bringing evidence-based practice to the bedside. Clin Nurse Spec 2006;20:124-7.

38. Weber A, Fournier R, Riand N, Gamulin Z. Duration of analgesia is similar when $15,20,25$ and $30 \mathrm{~mL}$ of ropivacaine $0.5 \%$ are administered via a femoral catheter. Can J Anaesth 2005;52:390-6.

39. Kennedy DM, Stratford PW, Wessel J, Gollish JD, Penney D. Assessing stability and change of four performance measures: A longitudinal study evaluating outcome following total hip and knee arthroplasty. BMC Musculoskelet Disord 2005;6:3.

40. Ho KY, Gan TJ, Habib AS. Gabapentin and postoperative pain a systematic review of randomized controlled trials. Pain 2006;126:91-101.

41. Peng PW, Wijeysundera DN, Li CC. Use of gabapentin for perioperative pain control - a meta-analysis. Pain Res Manage 2007;12:85-92.

42. Seib RK, Paul JE. Preoperative gabapentin for postoperative analgesia: A meta-analysis. Can J Anaesth 2006;53:461-9.

43. Sheen MJ, Ho ST, Lee CH, Tsung YC, Chang FL. Preoperative gabapentin prevents intrathecal morphine-induced pruritus after orthopedic surgery. Anesth Analg 2008;106:1868-72.

44. Tanabe M, Takasu K, Takeuchi Y, Ono H. Pain relief by gabapentin and pregabalin via supraspinal mechanisms after peripheral nerve injury. J Neurosci Res 2008;86:3258-64.

45. Cheng VY, Bonin RP, Chiu MW, Newell JG, MacDonald JF, Orser BA. Gabapentin increases a tonic inhibitory conductance in hippocampal pyramidal neurons. Anesthesiology 2006;105:325-33.

46. Felson DT, Lawrence RC, Dieppe PA, et al. Osteoarthritis: New insights. Part 1: The disease and its risk factors. Ann Intern Med 2000;133:635-46.

47. Guccione AA, Felson DT, Anderson JJ, et al. The effects of specific medical conditions on the functional limitations of elders in the Framingham Study. Am J Public Health 1994;84:351-8.

48. Kennedy DM, Stratford PW, Hanna SE, Wessel J, Gollish JD. Modeling early recovery of physical function following hip and knee arthroplasty. BMC Musculoskelet Disord 2006;7:100.

49. Terwee CB, van der Slikke RM, van Lummel RC, Benink RJ, Meijers WG, de Vet HC. Self-reported physical functioning was more influenced by pain than performance-based physical functioning in knee-osteoarthritis patients. J Clin Epidemiol 2006;59:724-31.

50. Boardman DL, Dorey F, Thomas BJ, Lieberman JR. The accuracy of assessing total hip arthroplasty outcomes: A prospective correlation study of walking ability and 2 validated measurement devices. J Arthroplasty 2000;15:200-4.

51. Kreibich DN, Vaz M, Bourne RB, et al. What is the best way of assessing outcome after total knee replacement? Clin Orthop Relat Res 1996;(331):221-5.

52. Freter SH, Fruchter N. Relationship between timed 'up and go' and gait time in an elderly orthopaedic rehabilitation population. Clin Rehabil 2000;14:96-101.

53. Ouellet D, Moffet H. Locomotor deficits before and two months after knee arthroplasty. Arthritis Rheum 2002;47:484-93.

54. Kennedy D, Stratford PW, Pagura SM, Walsh M, Woodhouse LJ. Comparison of gender and group differences in self-report and physical performance measures in total hip and knee arthroplasty candidates. J Arthroplasty 2002;17:70-7.

55. Walsh M, Kennedy D, Stratford PW, Woodhouse LJ. Perioperative functional performance of women and men following total knee arthroplasty. Physiother Can 2001;53:92-100.

56. Walsh M, Woodhouse LJ, Thomas SG, Finch E. Physical impairments and functional limitations: A comparison of individuals 1 year after total knee arthroplasty with control subjects. Phys Ther 1998;78:248-58. 


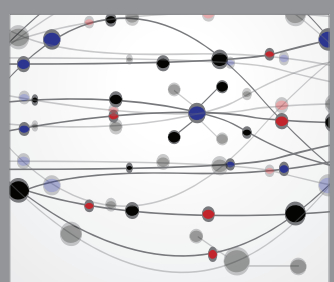

The Scientific World Journal
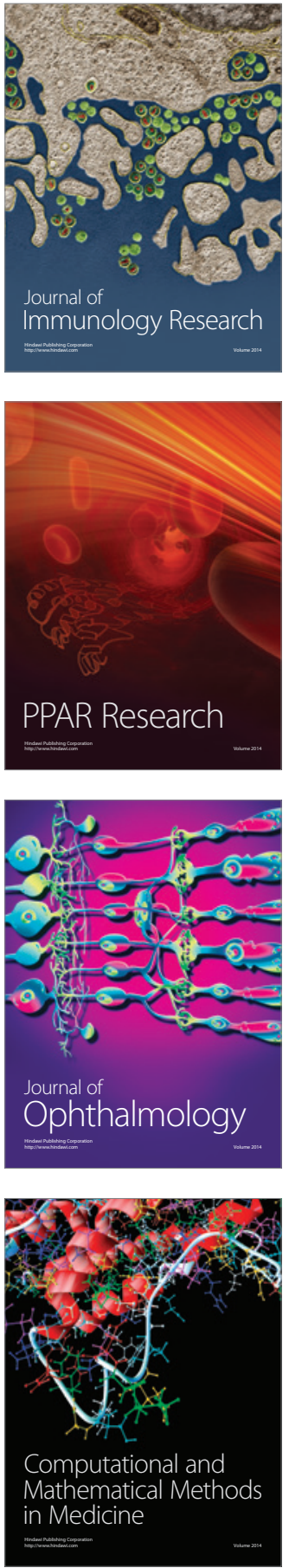

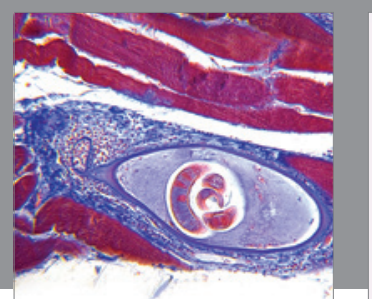

Gastroenterology Research and Practice

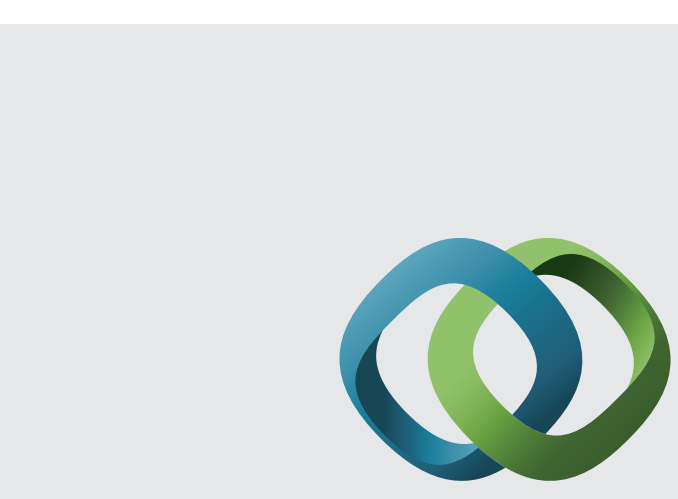

\section{Hindawi}

Submit your manuscripts at

http://www.hindawi.com
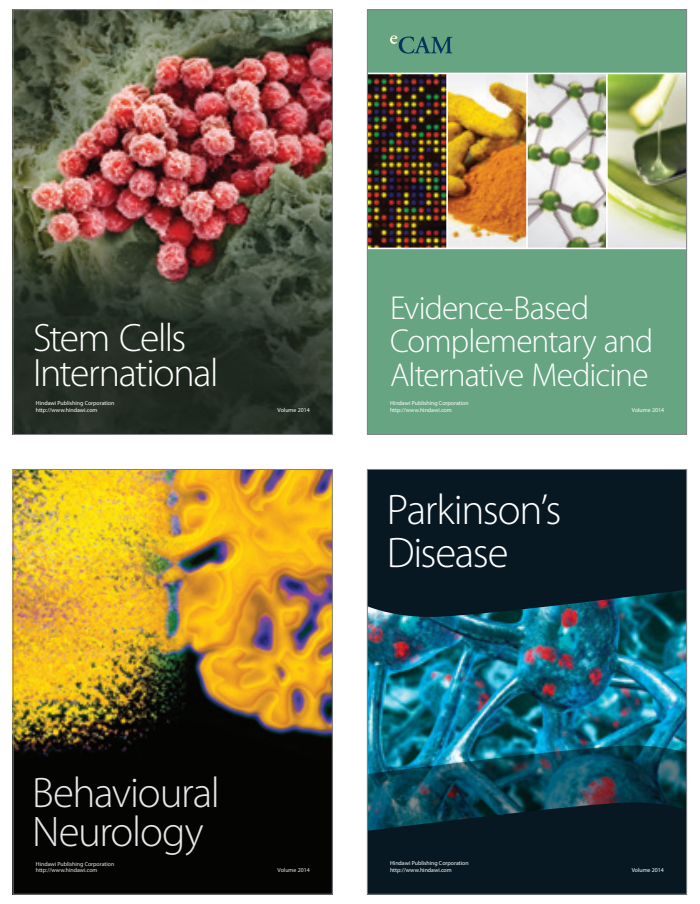
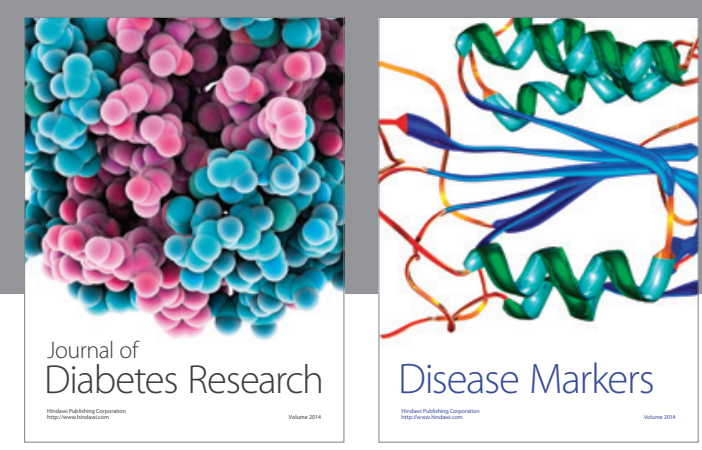

Disease Markers
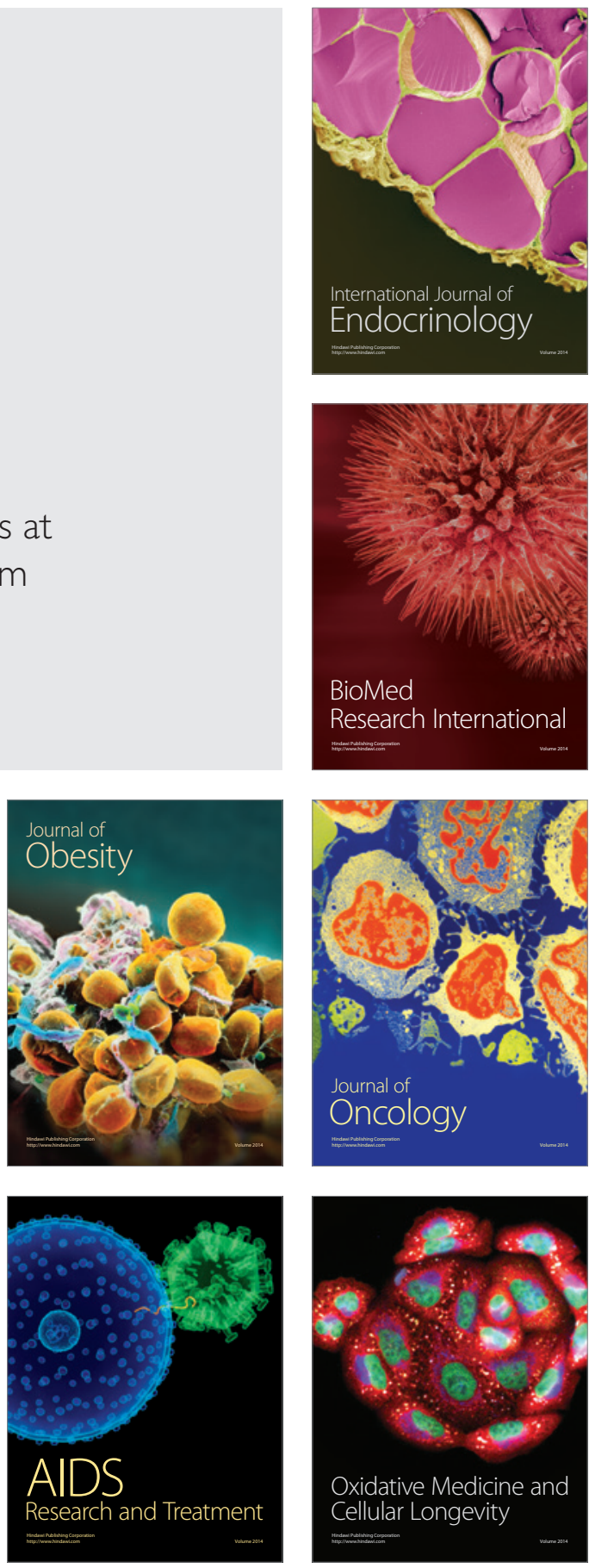